\title{
The Preservation of Fishing Nets by Treatment with Copper Soaps and Other Substances.
}

\author{
By \\ W. R. G. Atkins, F.I.C., F.R.S., \\ Head of the Department of General Physiology at the Plymouth Laboratory.
}

Is previous papers $(1925,1926)$ the writer published confirmations of the work of Taylor and Wells (1923), who had introduced to America the use of copper oleate dissolved in benzene or petrol. Within the last year a summary $(1927,1)$ of the results of further tests was published, also $(1927,2)$ a series of popular articles urging the adoption of certain of the methods tried. The object of the present paper is to set forth the details of the methods and the results, especially the tensile tests, obtained by a continuation of the work.

To avoid confusion in the nomenclature of the organic liquids used as solvents for the copper oleate (or other copper soap) it may be explained that by benzene the more or less impure mixture of benzene, $\mathrm{C}_{6} \mathrm{H}_{6}$, with toluene, $\mathrm{C}_{6} \mathrm{H}_{5} \cdot \mathrm{CH}_{3}$, is meant. This is a gas-works by-product and has a light brownish yellow colour. It is the best cheap solvent for these copper soaps, much better indeed than is pure benzene. The term petrol is reserved for the lighter portion of the petroleum distillate such as is used in motor-cars; it is known as gasoline in U.S.A. and elsewhere. This is a complex mixture of straight chain hydrocarbons with compounds having the benzene ring. Petrol from Sumatra has a larger proportion of the latter than has American petrol and may accordingly be expected to be a rather better solvent for the copper soaps. The heavier petroleum distillate, such as is used in lamps, is known in England as paraffin oil, in America as kerosene.

Copper oleate was not, however, used in the tests here once it had been established that a mixed copper soap was as effective, or more so. The latter has now been put on the market in Great Britain and contains stearates, palmitates, and oleates in the proportions in which they exist in a commercial product utilized in its manufacture. It is sold ready mixed with the 10 per cent of mineral lubricating oil recommended by Taylor and Wells to prevent the soap from creeping out of the fabric as the solvent evaporates.

Later on Taylor and Wells (1926) tried to improve their method by 
incorporating various binding agents with the soap. Trials on these lines have been in progress here, also experiments with "Cuprinol" alone and with binding agents. The writer is indebted to Dr. A. C. Johansen for having brought " Cuprinol " to his notice. This is not copper oleate, nor is it a mixture of fatty acid soaps such as the English product. It appears to be a preparation of copper salts of naphthenic acids derived from petroleum and is more soluble in petrol than are the fatty acid copper salts.

In view of the widespread use of cutch in net preservation it seemed advisable also to include it in the comparative tests, as though single treatments are much less durable than single treatments with copper oleate as shown by Taylor and Wells, it seemed possible that current practice was not as inadequate as has been imagined-the nets being cutched at intervals. Trials were also made according to Dr. Olie's Dutch method, in which after cutch the nets are immersed in ammoniacal copper sulphate.

The various methods of preservation tried were compared by placing the nets, usually about a metre square, in a jar of sea-water and allowing them to rot, the water being changed three times a week. The tests are truly comparable, though obviously the conditions do not approximate to those under which the nets are used, save as regards pound nets. Nets used from boats are, however, rarely quite dry, and rotting proceeds continuously in a slightly damp net. The rotting test is, however, more severe than practice, inasmuch as the damp net is not having the preservative leached out all the time ; it is less severe because the net, when in use, is subjected to a stream of water, so that removal of the preservative is more rapid than under the conditions of the experiments; again, the net in practice undergoes wear and tear to which the nets kept in the jars are not exposed.

In the first experiments made the strands of the nets were tested by hand. It was usually possible to tear the net about one month after the strands could thus be broken. When the net could be torn its serviceable life was considered at an end. In later work tensile tests were carried out upon the strands, using a spring balance. When the strands had deteriorated so as to be "too weak to test," the net was considered unserviceable. On the balance this corresponds to a strength of under four pounds. The condition of the net is then such that it can be torn and would be condemned by the hand test also.

In the course of the work certain facts bearing on all such tests became apparent:-

1. That it is always necessary to include an untreated net in each series, or when comparing two treatments to carry out the comparison simultaneously. This is rendered necessary by the different rates of 
rotting in summer and in winter or occasioned by differences in the water used.

2. That it is necessary to compare nets in jars of equal size.

3. That the purity of the water used has a very considerable effect upon the rate of rotting. Pure sea-water- "outside water"-being relatively poor in phosphates and nitrates, is not such a good medium for bacterial growth on the fibres as is water from the Aquarium tanks. In the early work outside water was used. Later on-and without at the time realizing how great was the difference - tank water was used on account of the large volume required by the numerous experimental jars. Tank water exerts its full effect upon the untreated controls. The nets treated with a good preservative are not affected at all till the preservative has been leached out, and there is no evidence that tank water does this any more rapidly than outside water. Tank water is, however, a nearer approach to having the nets fouled by fish than is outside water, so its use is advantageous. Since the damage due to fouling is occasioned by bacterial fermentation, leading to the production of heat in piled nets, it is obvious that so long as the net fibres are coated with an efficient preservative, namely, an antiseptic, the fermentation of fish slime, etc., on the outside can have relatively little effect on the net itself. Once the preservative has been leached out, however, such conditions lead to the very rapid decay of the net.

A short account will now be given of the methods of preservation employed, and the results will then be shown in tables.

\section{Treatment with Copper Oleate.}

The soap, a greasy greenish blue solid, is dissolved in benzene preferably ; but petrol was used for the experiments, as it is sufficiently soluble in it to make up a 10 per cent solution at room temperature, $15^{\circ} \mathrm{C}$. This was made 1 per cent with respect to mineral oil. The net was dipped in the solution till thoroughly wetted and then hung up to dry. The petrol evaporates quickly.

\section{Treatment with mixed Copper Soaps.}

(Pilot protective copper soap, manufactured by Messrs. Ogston and Tennant, Renfrew.)

Being less soluble than the oleate, this was at first used in 5 per cent solution in petrol. It is sold with the mineral oil already incorporated. This concentration is, however, far from being a saturated solution, and a 10 per cent solution was subsequently used in warm weather. Finally, as a standard mixture, one pound (454 grm.) to an Imperial gallon (4.54 litres) was adopted. This is close to a 12 per cent solution. It is 
most conveniently prepared by melting the soap by standing the tin in hot water and then adding a little petrol and mixing till the whole can be poured out. The petrol should be slightly warmed by hot water*; this is necessary in cool weather, much under $15^{\circ} \mathrm{C}$., and is always an advantage. The nets should be immersed in the solution till the liquid has penetrated into the knots fairly well. This object is attained when the whole appears thoroughly wetted and has stood five to ten minutes, though a longer immersion is recommended, when practicable. On hanging up to dry the petrol evaporates quickly. The treatment is best carried out in the open air, both to minimise risk of fire and because the vapour from petrol or benzene is apt to produce headache. For this reason a breezy day is most suitable with, if possible, sun to dry the nets. Care should be taken to do this thoroughly so that they may not give off inflammable vapour when piled up in a heap. Half an hour or an hour usually suffices for the drying.

\section{Treatment with Cutch.}

Cunningham (1902) showed that the portion of the cutch most effective as a preservative was that which was insoluble in cold water, but soluble in boiling water. Nets were accordingly boiled for half an hour in a 2 per cent infusion of cutch, using enough liquid completely to cover the nets. The nets were allowed to stand in the solution, after boiling, for twenty-four hours. They were then dried and re-treated with cutch in the same way as before. The cutch used was that sold for the purpose in Plymouth, "Caller Herrin" " brand (Bakau Co.). Experiments with cutch and a review of the literature are given by Taylor (1921) and need not be repeated here.

\section{Dr. Olie's (the Dutch) Treatment.}

The nets are first treated with cutch as already described, two boilings. When finally dried they are placed in a solution of ammoniacal copper sulphate. This is prepared by adding to a 1 per cent solution of the sulphate enough ammonia solution to re-dissolve the precipitate first formed, leaving a clear deep blue solution. The addition of 4 c.c. of strong (sp. gr. 0.88) ammonia solution to a litre $\dagger$ of the copper salt produces the desired effect. The nets are placed in this solution for not more than fifteen minutes. The solution is largely decolorized by the nets. The substances used are cheap and the treatment is simple and rapid. Care should be taken not to breathe the gas given off from the strong ammonia solution and to keep it from the eyes.

* A miner's safety lamp with absolutely intact gauze might also be used to keep the petrol warm, but it has not been tried here.

$\uparrow$ Namely, four volumes of ammonia solution to one thousand of copper solution. 


\section{Tar, Anti-fouling Paint, Resin.}

The tar used was the coal-distillation product. This varies somewhat in composition, which may account for the superior results given by certain experiments in which it was used as compared with others. It is stirred into the petrol solution containing copper soap, and mixes well, up to the maximum proportion used, one pound to the gallon.

The anti-fouling paint used was a red copper oxide preparation obtained from Messrs. Foster, Mason, and Harvey. It was stirred into the petrol solution of copper soap. The ounces mentioned are by weight $(1$ ounce $=$ $28 \cdot 3$ grams).

The difficulty that resin is insoluble in petrol was surmounted by melting it with the copper soap and then stirring up with petrol. Using one pound of resin to one of soap and a gallon of petrol a solution of low viscosity was obtained; this in time becomes thicker. The netting treated with this mixture dries readily and handling is a relatively clean business, which is not the case with nets freshly treated with the soap-tar or soap-paint mixtures.

\section{CUPRINOL.}

This is sold in liquid form. It is a mixture of 50 parts of the copper salts of crude acids separated from Russian or Galician petroleum dissolved in 36 parts of volatile petroleum (boiling range $85^{\circ}-250^{\circ}$ ) with 14 parts of heavy mineral oil.* It is manufactured by Aktieselskabet. Kymeia, Glentevej 61, Copenhagen. A five kilogram tin costs, when delivered in Plymouth, 16.25 Danish kroner. For use the manufacturers. recommend that it should be diluted with an equal volume of solvent naphtha, petrol ("gasolin "), or mineral paint oil. One kilogram of net. consumes about half its weight of mixed cuprinol. The $5 \mathrm{~kg}$. tin (roughly 5 litres), diluted with an equal volume of petrol (say, sp. gr. $0 \cdot 8$ ), gives $9 \mathrm{~kg}$. of mixture, which suffices for $18 \mathrm{~kg}$. of net at a cost of $16 \cdot 25 \mathrm{kroner}$ plus one gallon approximately of petrol (fifteen pence), total 19 shillings. The cost is therefore roughly one shilling per kilogram of net treated.

Cuprinol received a gold medal award in the International Fishery Exhibition at Copenhagen in 1912, and in spite of the danger of fire, urged as an objection to the use of copper soaps, it is still manufactured and used in Denmark. An English firm preparing a tender for tarpaulin covers for the Danish State Railways found that the specification embodied the use of Cuprinol.

On the same consumption basis, one half-kilogram of solution to one of net, using Pilot protective copper soap, at fifteen pence a pound with petrol at the same price per gallon, the cost of treating a $35 \mathrm{lb}$. herringnet would be as follows: Half weight of net, say $18 \mathrm{lbs}$, equivalent to

\footnotetext{
* Private communication.
} 
2 lbs. soap plus two gallons of petrol, cost $5 /-$ or $3 \frac{1}{3}$ pence per pound of net, which is much cheaper than cuprinol. However, for the actual treatment of one such net, to soak it properly, a larger volume of solution is required, up to about seven gallons, at a total cost of $17 / 6$. Much of the solution is, however, left-it is not all consumed. Neglecting the cost of labour, the treatment is estimated to add one shilling in the pound, or 5 per cent, to the cost of a cotton net.

Taking a herring net 55 yards long and 17 score meshes deep, $32 \frac{1}{2}$ rows to the yard, made up with ropes and floats, ready cutched, to be worth $£ 55 \mathrm{~s}$. and to weigh $39 \mathrm{lbs}$., and assuming that it completely uses up the seven gallons of soap solution, at $17 / 6$ the cost is still under 18 per cent on that of the net, whereas the life is much prolonged. On the above basis there can be no gain in the treatment unless the life of the net is prolonged by over 20 per cent; but to say that the cost is prohibitive - as has been said-when the life of the net is doubled or trebled or preserved even longer is scarcely correct mathematics.

\section{The Deterioration of Untreated Net.}

Table 1 shows how quickly the untreated controls, used in the preservation tests, became rotten. Outside sea-water is less severe than is tank water. There is no great difference between the rate at which hemp and cotton rot: in summer both are rotten in under two months, in winter in five to six.

\section{TABLE 1.}

Showing the time required for materials, having the initial tensile strength per strand of net as shown in column No. 2, to become unserviceable ; the date of immersion is shown in column No. 4.

\begin{tabular}{|c|c|c|c|c|c|}
\hline No. & lbs. & Material. & Immersed. & $\begin{array}{c}\text { Till } \\
\text { unserviceable, } \\
\text { months. }\end{array}$ & Medium. \\
\hline 7 & 14 & Hemp & $16 / 9 / ' 24$ & 7 & Outside sea-water. \\
\hline 10 & 14 & , & $26 / 9 / ' 25$ & 5 & Aquarium tank water. \\
\hline 28 & 18 & , & $17 / 3 / 26$ & 2 &,,$\quad$, \\
\hline $10 \mathrm{~A}$ & 22 & Cotton & $26 / 9 / 25$ & $5 \frac{1}{2}$ &, \\
\hline $15 \mathrm{~A}$ & 19 & , , & $7 / 11 / 25$ & $4 \frac{1}{2}$ & , \\
\hline $34 \mathrm{~A}$ & 18 & , , & $20 / 10 / / 26$ & $5 \frac{1}{2}$ & , \\
\hline $24 \mathrm{~A}$ & 12 & , & $17 / 3 / 26$ & 2 & , \\
\hline
\end{tabular}

\section{Preservation with Mixed Copper Soap and with Copper Oleate.}

In Table 2 it may be seen that the commercial copper soap, with mixed fatty acids, is at least as good as is pure copper oleate. There is an indication that the former is considerably better since the life of the net 
was about the same, though only half as concentrated a dip was used. It will be noted that the control perished under the cooler winter conditions-about two months would have sufficed in summer.

\section{TABLE 2.}

Hemp young fish trawl-net rotting in outside sea-water for seven months, then in aquarium tank water. Initial strength 14 lbs. per strand.

\begin{tabular}{|c|c|c|c|}
\hline No. & Treatment. & Immersed. & Till unserviceable, months. \\
\hline 7 & Untreated & $16 / 9 / 24$ & 7 \\
\hline 6 & oleate, $10 \%$ & & 14 \\
\hline 5 & Mixed copper soaps, $5 \%$ & $4 / 9 / / 24$ & $13 \frac{1}{2}$ \\
\hline 8 & $\begin{array}{l}\text { As No. } 5 \text {. Re-treated with } 12 \% \\
\text { mixed soaps after } 11,17,21 \text {, and } \\
24 \text { months }\end{array}$ & , & $\begin{array}{l}\text { Still two-thirds of original } \\
\text { strength after } 27 \text { months, } \\
4 / 12 / 26 \text {. }\end{array}$ \\
\hline
\end{tabular}

\section{Preservation with Mixed Copper Soaps (Pilot Protective Copper Soap) reinforced with Anti-fouling Paint, Tar or Resin.}

Tables 3 and 4 show the results obtained with hemp; 5, 6, and 7 with cotton. Resin gives a net which is very clean to handle, using it pound for pound with soap, which is the best proportion of those tried; it is an improvement, up to about 50 per cent on soap alone on hemp; on cotton, however, it is well over twice as good as soap alone. It was feared at one time that the use of resin, favourable under water, might result in weakening of the fibre in nets exposed to air and light to dry. Direct tests using fabrics continuously exposed on the roof fortunately disproved this. The soap-resin mixture leaves the net green in colour and very pliable.

Anti-fouling paint enormously increases the life of the net, even using a few ounces to each pound of soap. It leaves the net a red colour, very pliable and greasy, soiling the hands for months in the pound for pound proportion. On the score of cleanliness and cost half a pound or less might be used.

Tar, too, has given excellent results in the pound for pound proportion (see Nos. 14 and 14A). This amount does not make the net any way stiff, for the soap is a thick grease.

The experiments in Table 7, designed to show the best small proportion of tar, have unfortunately proved inconclusive, for all perished simultaneously. Moreover, the pound for pound mixture, No. 51A, had a life of only 11 months, whereas No. 14A, similarly treated, has maintained its original strength after 26 months. One can but suggest some difference in the tar; probably it was a tar in which distillation had been pushed too far, leaving a brittle product on drying. 


\section{TABLE 3 .}

Hemp net rotting in Aquarium tank water ; initial strength, average of sets of six, $13 \frac{1}{2}$ lbs. and $14 \frac{3}{4}$ lbs. dry ; after soaking for three hours, $12 \frac{1}{2}$ lbs. Immersed 26/9/'25.

\begin{tabular}{llcc} 
No. & \multicolumn{1}{c}{ Treatment. } & $\begin{array}{c}\text { Till unserviceable, } \\
\text { months. }\end{array}$ & $\begin{array}{c}\text { Percentage } \\
\text { life of net. }\end{array}$ \\
10 & Untreated & 5 & 100 \\
11 & Copper soaps, $12 \%$ & 9 & 180 \\
$12 \dagger$ & Do. with resin 1 lb. per gallon $(12 \%)$ & 11 & 220 \\
13 & Do. with anti-fouling paint, $12 \%$ & $26+\mathrm{x}$ & $500+\mathrm{y}^{*}$ \\
14 & Do. with tar, $12 \%$ & $26+\mathrm{x}^{\prime}$ & $500+\mathrm{y}^{\prime} \ddagger$
\end{tabular}

* Half strength, still serviceable, looks as new.

$\dagger$ The soap and resin, paint, or tar respectively were mixed, so that only one dip was required.

$\ddagger$ Slightly under half strength, still serviceable, looks as new.

\section{TABLE 4.}

Hemp net rotting in Aquarium tank water; initial strength, dry, 14 lbs. Immersed 17/10/'25.

\begin{tabular}{llll} 
No. & \multicolumn{3}{c}{ Treatment. } \\
15 & Copper soap 1 lb., resin $\frac{1}{4}$ lb. per gallon \\
16 & Do. & , & $\frac{1}{2}$ lb. \\
17 & Do. & , & l lb.
\end{tabular}

Till unserviceable, Percentage

$\begin{array}{cc}\text { months. } & \text { life of net. } \dagger \\ 12 * & 240 \\ 12 & 240 \\ 14 \frac{1}{2} & 290\end{array}$

$\dagger$ Taking No. 10, immersed 26/9/'25 as control, life 5 months.

* Nos. 15 and 16 were $81 \mathrm{lbs}$. and $11 \mathrm{lbs}$. respectively after $11 \frac{1}{2}$ months, but were too weak to test after $12 \frac{1}{2}$. No. 17 , which was $11 \frac{1}{2} \mathrm{lbs}$. after $11 \frac{1}{2}$ months, decreased gradually to $5 \mathrm{lbs}$. after $14 \frac{1}{2}$ months, so was perhaps serviceable up to 15 months.

\section{TABLE 5 .}

Cotton net rotting in Aquarium tank water ; initial strength, dry, $19 \frac{1}{2}$ lbs. Immersed 26/9/'25.

\begin{tabular}{ll} 
No. & \multicolumn{1}{c}{ Treatment. } \\
$10 \mathrm{~A}$ & Untreated \\
$11 \mathrm{~A}$ & Copper soaps, $12 \%$ \\
$12 \mathrm{~A} \dagger$ & Do. with resin 1 lb. per gallon $(12 \%)$ \\
$13 \mathrm{~A}:$ Do. with anti-fouling paint, $12 \%$ & \\
$14 \mathrm{~A} *$ & Do. with tar, $12 \%$
\end{tabular}

Till unserviceable, Percentage months. life of net.
10A Untreated
$11 \mathrm{~A}$ Copper soaps, $12 \%$
$13 \mathrm{~A}$. Do. with anti-fouling paint, $12 \%$
$14 \mathrm{~A}^{*}$ Do. with tar, $12 \%$

$\begin{array}{cc}5 \frac{1}{2} & 100 \\ 10 \frac{1}{4} & 190 \\ 26+\mathrm{x} & 470+\mathrm{y} \\ 26+\mathrm{x}^{\prime} & 470+\mathrm{y}^{\prime} \\ 26+\mathrm{x}^{\prime \prime} & 470+\mathrm{y}^{\prime \prime}\end{array}$

+ No. $12 \mathrm{~A}$ is still over half strength, $10 \mathrm{lbs}$.

1* Nos. 13A and 14A look as new, neither paint nor tar now soil the hands. They are stronger than before treatment, 26 and 24 lbs. respectively; this may be partly due to cementation of the fibres, partly to inequality in strength of the strands. 


\section{TABLE 6.}

Cotton net rotting in Aquarium tank water; initial strength, dry, $19 \frac{1}{2}$ lbs. Immersed $7 / 11 / 25$, in smaller jars than in the other tests.

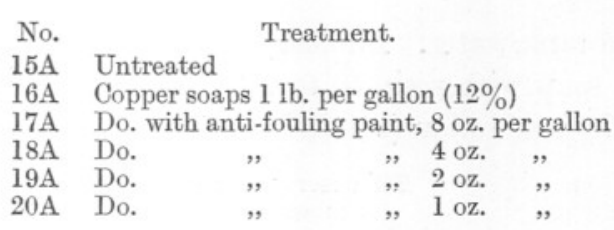

$\begin{array}{cc}\text { Till unserviceable, } & \text { Strength after } \\ \text { months. } & 23 \text { months. } \\ 4 \frac{1}{2} & 0 \\ 23+x & 16 \frac{1}{2} \\ ,, & 17 \frac{1}{2} \\ , & 19 \frac{1}{2} \\ , & 22 \frac{1}{2} \\ , & 29\end{array}$

\section{TABLE 7.}

Cotton net rotting in Aquarium tank water ; initial strength, dry, 12 lbs. Immersed 18/11/26. Life, eleven months.

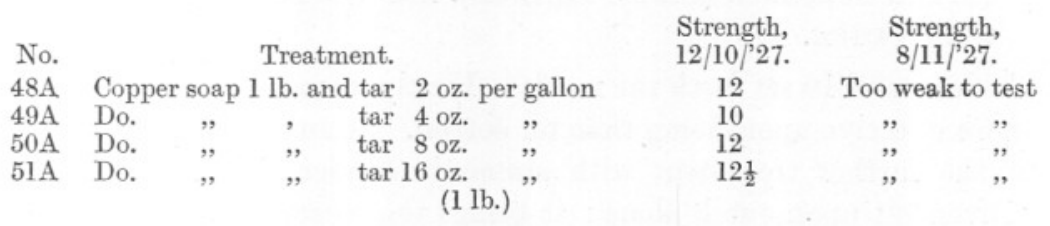

Preparation of Copper Soap for Issue in a Liquid Form.

A pound of soap (as supplied, ready mixed with one-tenth its weight of mineral oil) was melted and a pound of powdered resin or of tar was stirred in. To the mixture a pound and a half of carbon tetrachloride was added. The result is a mobile liquid which becomes thicker when cold, or even gelatinous if left overnight at $10^{\circ} \mathrm{C}$. It becomes liquid in a warm room at $15^{\circ} \mathrm{C}$. Carbon tetrachloride is non-inflammable-it is used in fire extinguishers - but is volatile and gives off a heavy vapour similar to chloroform in its action when breathed. It was chosen on account of its non-inflammable nature and because it is the cheapest suitable solvent, costing about one shilling per pound. Since the copper soap coats only fifteen pence per pound, the use of the liquid preparation more than doubles the cost, but it can of course be mixed with the main solvent, petrol or benzene, very readily.

\section{Use of Paraffin instead of Petrol as Solvent.}

With the object of producing a mixture that could be used and stored under conditions of comparative safety against fire, under " fool-proof " conditions, paraffin oil of high flash-point, such as used in lamps, was used as solvent with the carbon tetrachloride liquid soap mixtures mentioned in the last section. The results show that the increase in the life 
of the net is not nearly as good as when petrol is used as solvent (see Table 8). These poor results need not be attributed to the use of carbon tetrachloride, for it evaporates quickly, leaving no residue.

\section{TABLE 8 .}

Cotton net rotting in Aquarium tank water. Immersed 5/1/26. Solvent for the melted mixture of soap with resin or tar, first carbon tetrachloride, $1 \frac{1}{2} \mathrm{lbs}$., followed by one gallon (about $8 \mathrm{lbs}$.) of paraffin oil.

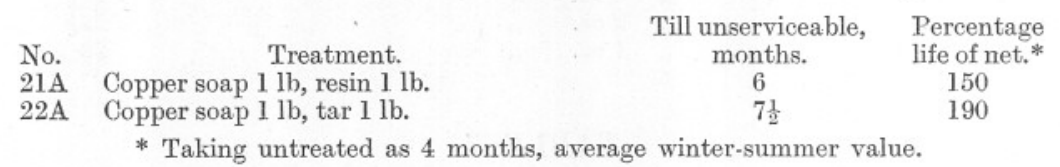

\section{A Comparison of Treatment with Cutch, Cutch and Ammonia Copper Sulphate (Olie's Method), and Copper Soap alone and wITH CUTCH.}

Tables 9 and 10 set forth the results. Firstly, it may be seen that cutch is more effective upon hemp than on cotton. Secondly, it is established that the further treatment with ammonia copper sulphate is a great improvement upon cutch alone ; it brings the treatment up to the level of that with copper soap alone (short dip) for cotton, and surpasses it for hemp. Olie's method is rapid and cheap. It has much to recommend it, though it is nothing like as effective as copper soap with tar or antifouling paint on cotton. A comparison of Nos. 31 and 32 shows that treatment with cutch before copper soap is an advantage with hemp, though Nos. $27 \mathrm{~A}$ and $28 \mathrm{~A}$ give no indication that it is any advantage with cotton. Fillon (1925), however, considers it an advantage on cotton also. In this series No. $30 \mathrm{~A}$ is by far the best; though soap and resin may be inferior to soap alone (Nos. 32 and 33) when the latter is allowed to soak thoroughly, or much better (Nos. 11A, 12A, 11 and 12), yet a first dip in soap, followed by a second in soap and resin, undoubtedly gives excellent results. The cost is, of course, about doubled, since the solvent is the chief item; but as compared with soap and tar or soap and anti-fouling paint there is the great advantage of a net which is quite clean to handle.

As regards the duration of soaking in copper soap solution, No. 28A compared with No. $11 \mathrm{~A}$ shows the percentage life of the net to be 250 and 190 respectively, which is in favour of the longer time of soaking. (The actual life of the net 11A was longer, twice as long as that of $28 \mathrm{~A}$, but the former was rotting in winter and was an $18 \mathrm{lb}$. strand as against a $12 \mathrm{lb}$.) With hemp the improvement is more marked, a single treatment with 3 hours' soaking having preserved the net for 19 months. 


\section{TABLE 9.}

Hemp net rotting in Aquarium tank water ; initial strength, dry, averages of sets of six tests each, $15 \frac{1}{4}, 15 \frac{3}{4}, 18 \frac{1}{2}$; maximum single strand 21 , minimum $12 \frac{1}{2}$. Immersed 17/3/'26.

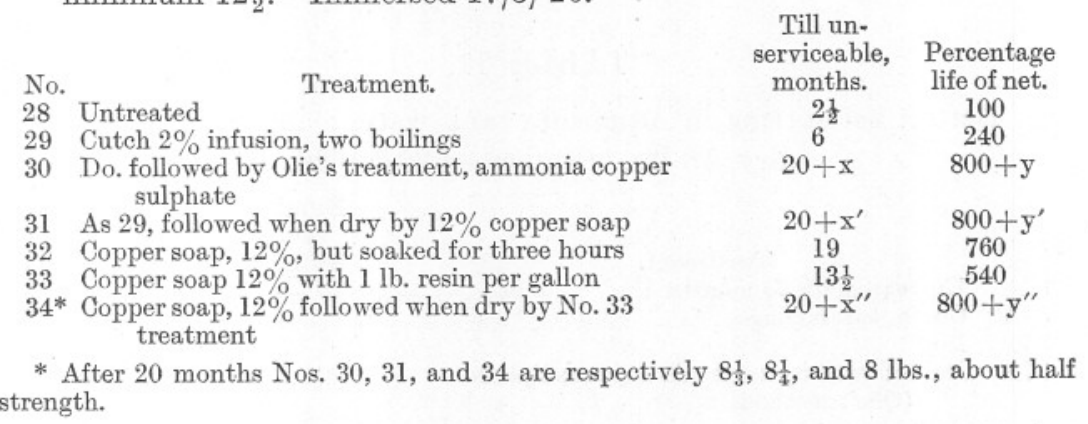

\section{TABLE 10.}

Cotton net rotting in Aquarium tank water; initial strength, dry, 12 lbs. Immersed 17/3/’26.

No.

24A Untreated

$26 \mathrm{~A}$ Cutch, $2 \%$ infusion, two boilings

25A Do. followed by Olie's treatment, ammonia copper sulphate

$27 \mathrm{~A}$ As $26 \mathrm{~A}$, followed when dry by $12 \%$ copper soap

$28 \mathrm{~A}$ Copper soap, $12 \%$, soaked three hours

$29 \mathrm{~A}$ Do. with $1 \mathrm{lb}$. resin per gallon

$30 \mathrm{~A}$ As $28 \mathrm{~A}$, followed when dry by $29 \mathrm{~A}$ dip

$\begin{array}{cc}\begin{array}{c}\text { Till un- } \\ \text { serviceable, } \\ \text { months. }\end{array} & \begin{array}{c}\text { Percentage } \\ \text { life of net. } \\ 2\end{array} \\ 3 & 100 \\ 5 & 150 \\ & 250 \\ 5 & 250 \\ 5 & 250 \\ 5 & 250 \\ 20+\mathrm{x}^{*} & 1000+\mathrm{y}\end{array}$

* Colour all gone by 17/11/'27, strength $7 \frac{1}{2} \mathrm{lbs}$.

\section{Re-treatment of Nets with Cutch and by Olie's Method.}

The results of the above treatments having proved better on hemp than on cotton nets, it seemed advisable to select the latter for a study of the effect of repeated treatments, especially as cutch is so largely used. The cutch bichromate method, introduced by Cunningham, was not tried at all since Taylor and Wells (1923) showed conclusively that it was inferior to the Dutch method with ammonia copper sulphate, though considerably superior to cutch alone. Taylor and Wells also showed that the various coal tar and pine tar treatments were inferior to copper soap. A summary of their most recent work (1926) is included at the end of this paper.

Table 11 contains the results of one year's immersion tests. It may be seen that by boiling again with cutch every two or three months the original strength has been retained, or very nearly so. Two re-treatments with cutch and ammoniacal copper sulphate in the course of the year 
suffice to keep the net quite sound. These nets, however, feel rather harsh to the hand, and the cutched nets give a very clean break in the tensile test. The nets have not the softness and pliability of those treated with copper soap with or without tar or anti-fouling paint.

\section{TABLE 11.}

Cotton net rotting in Aquarium tank water ; initial strength, dry, 18 lbs. Immersed 20/10/26.

37A Untreated, life $5 \frac{1}{2}$ months

$35 A^{*}$ Cutch, two boilings

36A Do.

37A Do. followed by ammonia copper sulphate (Olie's method)

$\begin{array}{cc}\text { Number of } & \\ \text { times } & \text { Strength after } \\ \text { re-treated. } & 12 \text { months. } \\ - & 0 \\ 4 & 16 \frac{1}{3} \\ 3 & 18 \\ 2 & 22 \frac{1}{2}\end{array}$

* No. 35A was re-treated every two months, irregularly, viz. on $20 / 12$ /'26, $3 / 3 /$ '27, $3 / 5 / 27,23 / 8 / 27,20 / 10 / 27$. No. 36A was re-treated every three months, viz. 20/1/'27, $20 / 4 / ' 27,20 / 8 / 27$ one month late. No. $37 \mathrm{~A}$ was re-treated on $3 / 3 / ' 27$ and $20 / 8 / 227$.

Comparison of Copper Soap (Pilot Protective Copper Soap) with Cuprinol, with and without Tar, in Fresh and in Salt Water.

Tables 12 and 13 record the results of one year's immersion on nets treated as shown. Nos. 35, 37, 40, and 42 prove that Cuprinol is better than the fatty acid soap mixture for preserving hemp in both salt and fresh water. As regards cotton, there are indications that Cuprinol will prove to be the better; even though No. $45 \mathrm{~A}$ is somewhat below the others in strength the preservative is still on it all over; the lower tensile values may be due to variation in the net. As far as results extend, tar and fatty acid copper soap are about as good as Cuprinol alone, and a mixture of the two soap products is also good. Longer periods are required to differentiate between these mixtures and Cuprinol with tar.

\section{TABLE 12.}

Hemp net Nos. 35-39 rotting in Aquarium tank water; Nos. 40-44 in fresh water. Immersed 25/11/227. Initial strength, dry, $16 \frac{1}{2} \mathrm{lbs}$.

\begin{tabular}{llc} 
No. & \multicolumn{1}{c}{ Treatment. } & Strength after 12 months.* \\
35 & Copper soap, $12 \%$ & $5 \frac{1}{3}$ green all gone. \\
36 & Do. with tar as No. 14 & $14 \frac{1}{3}$ good brown. \\
37 & Cuprinol with equal volume of petrol & $12 \frac{1}{3}$ green in patches. \\
38 & As No. 37 with 1 lb. tar per gallon of mixture & $16 \frac{1}{3}$ light black. \\
39 & Copper soap as No. 35, Cuprinol as No. 37, equal & 13 green in patches. \\
\multicolumn{2}{c}{ volumes of solution } & \\
40 & As No. 35 & 7 green all gone. \\
41 & As No. 36 & 9 good brown. \\
42 & As No. 37 & 14 good green all over. \\
43 & As No. 38 & $13 \frac{1}{2}$ good brown. \\
44 & As No. 39 & 12 good green all over
\end{tabular}




\section{TABLE 13.}

Cotton net Nos. 38A-42A rotting in Aquarium tank water; Nos. 43A-47A in fresh water. Immersed 25/11/26. Initial strength, $18 \frac{1}{2} \mathrm{lbs}$., done on $40 \mathrm{~A}$ before treatment, $17 \frac{1}{2} \mathrm{lbs}$. done on $45 \mathrm{~A}$ similarly, average $18 \mathrm{lbs}$.
No.
38 A Copper soap, $12 \%$
Treatment.
Strength after 12 months.*
$39 \mathrm{~A}$ Do. with tar as in $14 \mathrm{~A}$
$40 \mathrm{~A}$ Cuprinol with equal volume of petrol
22 green colour gone.
$11 \dagger$ good dark brown.
25 green colour retained in patches.
41A Cuprinol as $40 \mathrm{~A}$ with tar, $1 \mathrm{lb}$. per gallon of mixture 25 colour a light black.
$42 \mathrm{~A}$ Copper soap as $38 \mathrm{~A}$, Cuprinol as $40 \mathrm{~A}$, equal volumes $25 \frac{1}{3}$ green colour all gone.
$43 \mathrm{~A}$ As $38 \mathrm{~A}$ of solution
$44 \mathrm{~A}$ As $39 \mathrm{~A}$
$45 \mathrm{~A}$ As $40 \mathrm{~A}$
$46 \mathrm{~A}$ As $41 \mathrm{~A}$
$47 \mathrm{~A}$ As $42 \mathrm{~A}$
22 green in patches.
21 good black.
$16 \frac{3}{2}$ good green all over.
21 good black.
26 good green all over.

* Tested 16/11/'27.

$\dagger$ Evidently a weak piece of the original fibre, for when repeated on 18 th the average of the six tests was $18 \frac{1}{3}$ lbs.

\section{Results obtained by Taylor and Wells.}

The following quotations from the 1926 paper of these American workers will serve to bring their extensive series of tests to the notice of net users in this country.

"The tests were made in salt water at two places in the Atlantic Ocean, one place in the Pacific, and in fresh water at four places."

"The principal results and conclusions drawn from the present work are as follows :-

1. The combination of copper oleate with coal tar was the best preservative of tensile strength of those used.

2 . Both the proprietary waterproofing material and the proprietary wood preservative did some good as preservatives, but neither one was as effective as copper oleate or coal tar.

3. At all places where tests were made linen lines, both treated and untreated, were completely rotten in less than two months.

4. Azulmic acid, a dye tested as a preservative, proved to be of no value for this purpose.

5 . The combination of rare earths and copper oleate was very little better than copper oleate used alone.

6. Combinations of copper oleate with paraffin, boiled and raw linseed oil did not preserve tensile strength any better than copper oleate alone.

7. The copper oleate and linseed oil combinations appeared to wash out less rapidly than copper oleate alone, but did not prevent fouling by marine growth as well.

8. With the exception of the quercitron-ammoniacal copper sulphate treatment, the effectiveness of the several preservatives is of the same order on hemp as on cotton.

9. For hemp lines the copper oleate coal tar mixture was the best preservative of tensile strength, copper oleate coming second at all places except Fairport, Iowa, where coal tar was second best.

10. The quercitron-ammoniacal copper sulphate treatment (L) did not make as good a showing on cotton samples in the 1923 tests as it did in 1922 . We do not know of any cause for this other than that due to the variation in water conditions at different localities and in the same locality from one year to another.

11. The quercitron-ammoniacal copper sulphate treatment $(\mathrm{L})$ made a very poor showing on hemp samples. The hot-water solution of quercitron seems to damage hemp, causing an exceedingly large diminution in tensile strength, and probably is the cause of the poor results of this treatment on hemp. 
12. In fresh water of the Mississippi River at Fairport, Iowa, sample lines suffered more rapid deterioration than at any other point where tests were made. Coal tar preserved cotton lines at Fairport for three months. Lines treated by all other methods were completely rotten after two months' exposure.

13. Twine that is removed from the water every 30 days, dried, and treated with copper oleate lasts more than twice as long as that which is treated but once.

14. In fresh water at Put in Bay, Ohio, results with copper oleate were more satisfactory than in the previous series there.

15. The results at Put in Bay, Ohio, indicate that the rate of deterioration of nets not only varies from one locality to another, but differs in different years in the same locality.

(L) Quercitron and ammoniacal copper sulphate (called Dutch method in former paper). The lines were steeped in a hot solution of quercitron, $1 \mathrm{lb}$. to 2 gallons of water, until the solution was cold, dried, again steeped in the same way, and again dried. They were then immersed for a few minutes in an ammoniacal solution of copper sulphate containing one pound of copper sulphate and 3 pounds of 25 per cent ammonia for every $12 \frac{1}{2}$ gallons of water. For a full description of this method see Olie (1918)."

The following section is also quoted from Taylor and Wells: "Results of Practical Application of Copper Oleate by Fishermen."

"During the 1923 season between 60,000 and 100,000 pounds of copper oleate were used by fishermen. In order to determine whether these practical trials had produced satisfactory results, we visited the fishermen along the New England and middle Atlantic coasts, examined their nets, and obtained from them their observations and opinions. Lobster and pound-net fishermen from Maine to Long Island have, with few exceptions, had excellent results. At the time the survey was made copper oleate had been tried on but a very few gill nets in this region.

Those fishermen who used copper oleate found that it was an excellent anti-fouling agent and preservative as long as it remained in the twine. The length of time during which it remained in the twine varied from 14 days to 5 or 6 months. In those cases where it washed out in 14 days the fishermen believe the grade of copper oleate used was very poor.

Various combinations of copper oleate with other substances were tried by the fishermen. One of the most successful of these was a mixture of a small amount of copper paint with the kerosene solution of copper oleate. This is reported as being an excellent preservative for use on pound nets.

The fishermen were about equally divided in their opinions as to whether gasoline or kerosene [namely, petro! or paraffin oil] gave better results as a solvent. Gasoline seems to give a more uniform distribution of oleate through twine, drys more rapidly, and leaves twine less oily than kerosene. On the other hand, kerosene is cheaper than gasoline and also safer, because it is not inflammable. It was also found that in most cases better results were obtained when the net or webbing was allowed to steep in the solution for several hours, preferably over night, instead of 5 or 10 minutes, as was first recommended.

The principal suggestions from users of copper oleate were as follows :-

1. Steps should be taken to prevent copper oleate from washing out of the webbing as rapidly as it now does.

2. There is need for some substance which, when combined with copper oleate, will give it more hody, so that the webbing will be better protected from mechanical wear.

3. When copper oleate is used on seines, some substance should be added to prevent the slipping of knots when the seine is hauled.

With respect to the first of these suggestions, one must remember that if copper oleate is to prevent growth successfully it is necessary for it to be at least slightly soluble in water. An entirely insoluble substance would not preserve at all. It is doubtful, there. fore, if it would be advisable to decrease the solubility of copper oleate to any great extent. We have conducted experiments that have indicated that if the solubility is appreciably decreased by such substances as linseed oil or paraffin, copper oleate is less effective as an anti-fouling agent.

In regard to the second and third suggestions, it has been found from our experiments that a mixture of copper oleate and coal tar makes an excellent preservative ; in fact, one of the most effective tested. Where considerable increase in weight and stiffiness is objectionable, such a treatment, of course, would not be permissible. This treatment would also eliminate the slipping of knots." 


\section{GENERAL DISCUSSION.}

As regards Taylor and Wells' conclusion that copper oleate and coal tar treatment is excellent as a preservative the writer is in complete agreement, but less tar was used here. It should be noted, however, that the soap used here was not-save at first-oleate, but a mixture containing oleate. There is no doubt that with this petrol secures better penetration than does paraffin. To use paraffin is a very false economy. It must be pointed out also that quercitron, though a tanning agent, is not the same as the cutch (from acacia) used by Olie, nor did they boil the solution. Fillon (1925) has obtained very good results with Olie's ammonia copper sulphate method, particularly using a second treatment with one cutching followed by the copper dip. Fillon gives the following figures for the percentage increase in weight after various treatments : Cutching followed by ammoniacal copper sulphate, double application $30 \%$; copper oleate and coal tar (oleate 1 , benzene 8 , tar 8 ), $65 \%$-it should be noted that the mixture used here contains tar 1, not 8; copper oleate alone $(15 \%$ in petrol), $18 \%$; coal tar diluted with an equal part of benzene, $68 \%$. The results obtained here in which copper soaps with tar were superior to Olie's method were carried out with less tar than were those of Fillon or of Taylor and Wells. However, a second initial treatment was not given. Particularly good results were obtained here using Olie's method on hemp. This is in direct contradiction of the finding of Taylor and Wells using quercitron. It is curious also that their linen lines rotted so quickly, for though linen line rots in less than two months in Aquarium water in summer in tap water (which is, however, pure) it lasts several times as long.

As regards the slipping of the knots in nets treated with copper soap, this may be avoided by pulling them tight by hand before treatmenta general practice hereabouts before nets are used-or they may be cutched first and then treated with copper soap and tar. As regards the oleate remaining "in the twine" for 14 days to 5 or 6 months, it seems obvious that the shorter period recorded was due to poor penetration. occasioned probably by treatment of nets which were not thoroughly dry, or in very cold weather. Moreover, although nets may look quite colourless, they are not necessarily devoid of copper soap. This is shown by the fact that they remain intact for two or three months longer and finally become black as they rot, the black being copper sulphide produced from the remainder of the soap. Untreated nets never become black in this way.

The writer has been informed that the cutch and bichromate method in one locality replaced that with ammonia copper sulphate. This, according to Olie's results, is a retrograde move, and no results in the 
literature show the bichromate method to be at all as good as the latter. The two were not compared here, as the question was regarded as finally decided in favour of Olie's method. For this treatment, double application, Fillon gives the increase in weight as $30 \%$, that for oleate alone being $18 \%$; the copper soap and tar ( $1 \mathrm{lb}$. to $1 \mathrm{lb}$.) used here would therefore give about $30 \%$, for nly the soap and tar remain on the net. Using less tar or anti-fouling paint the weight might be reduced to $20-25 \%$. Since less water is taken up by a net already impregnated with the greasy soap-tar mixture, the actual increase in the hauling weight must be small.

\section{SUMMARY.}

1. Under the conditions of the tests cotton and hemp nets became rotten in Aquarium tank water in two months or less in summer, in $4 \frac{1}{2}-5 \frac{1}{2}$ months in winter.

2. A mixed copper soap, containing oleate, stearate, and palmitate, is as good, probably rather better, than is copper oleate as a net preservative.

3. "Cuprinol," a petroleum acid copper soap, is better than the fatty acid soaps, both in fresh and in salt water. It is more than three times as expensive, however.

4. The following specially good results have been obtained: Mixed fatty acid copper soap, $1 \mathrm{lb}$. with $1 \mathrm{lb}$. of coal tar or anti-fouling paint in a gallon of petrol, hemp nets about half strength, cotton nets full strength, after 26 months. Also copper soap $1 \mathrm{lb}$. to gallon, followed by a dip in copper soap 1 lb., resin 1 lb., petrol 1 gallon, hemp net about half strength, cotton net the same, after 20 months. The controls perished in $2 \frac{1}{2}$ and 2 months respectively. In this series cutch and copper soap and Olie's method did well, half strength after 20 months, on hemp, but lasted only 5 on cotton. A repetition of Olie's treatment twice in the course of the year was, however, found to preserve the cotton well. Fillon recommends a double Olie treatment at the very start and shows that nets so treated were sound after 18 months, as were also those cutched before copper oleate and coal tar treatment.

5. From the experiments carried out here it may be concluded that by far the best initial treatment for nets is one with a copper soap reinforced with anti-fouling paint or coal tar. On the score of shrinking the knots, as well as for preservation, a preliminary cutching appears to be advantageous. It is, however, doubtful whether Olie's ammoniacal copper sulphate treatment, repeated from time to time, may not be more suitable on account of its low cost. 


\section{REFERENCES.}

Atkins, W. R. G. 1925. The preservation of fishing nets, mosquito nets, and tent fabrics. Nature, 115, 761.

Atkins, W. R. G. 1926. Notes on the preservation of fishing nets by means of copper soaps. J. Marine Biol. Assoc., 14, 63-69.

Atkins, W. R. G. 1927. 1. Preservation of fishing nets. Fishing News, 14 , No. 715 , p. 31 ; No. 717 , p. 57 ; No. 719 , p. 8 ; No. 721 , p. 39.

Atkins, W. R. G. 1927. 2. The methods of using copper soaps to preserve fishing nets. J. du Cons. Internat. pour l'Exploration de la Mer, 2, No. 2, 144-150.

Cunningham, J. T. 1902. The preservation of fishing nets. pp. 64 . London.

Fillon, R. 1925. Les traitements préservateurs des filets de pêche en coton. Office sci. et tech. des pêches maritimes. Notes et mém. No. 45. Paris.

OLIE, J., Jr. 1918. Voorschriften voor de behandeling van netten met kopersulfaat en ammonia. pp. 40-42. Verslag van der directeur van het Nederlandsch Visscherij-Prœfstation over het jaar 1917.

TAYLOR, H. F. 1921. Preservation of fish nets. U.S.A. Bureau of Fisheries Document, No. 898.

Taylor, H. F., and Wells, A. W. 1923. Properties and values of certain fish-net preservatives. Loc. cit., Doc. No. 947.

TAylor, H. F., AND Wells, A. W. 1926. Further experiments on the preservation of fish nets. Loc. cit., Doc. No. 998. 
